\title{
Commentary \\ Does the act of surgery provoke activation of "latent" metastases in early breast cancer?
}

\author{
Michael Baum
}

Emeritus Professor of Surgery, University College London, London, UK
Corresponding author: Michael Baum, michael@mbaum.freeserve.co.uk

Published: 9 June 2004

Breast Cancer Res 2004, 6:160-161 (DOI 10.1186/bcr902)

(c) 2004 BioMed Central Ltd

See related Research article: http://breast-cancer-research.com/content/6/4/R372

\begin{abstract}
This paper is written in support of the challenging article by Retsky and colleagues in this issue of Breast Cancer Research, and develops on the idea that the act of surgery can provoke the outgrowth of dormant micrometastases, which often leads to the failure of screening to deliver its promise. The therapeutic consequence of this idea involves the use of antiangiogenic drugs before surgery.
\end{abstract}

Keywords: angiogenesis, breast cancer, latent metastases, surgery, screening theory

The short paper by Michael Retsky and his colleagues in the current issue of Breast Cancer Research is, I believe, of revolutionary importance in the history of the understanding of breast cancer [1]. Unfortunately, its title, "Hypothesis: Induced angiogenesis after surgery in premenopausal node-positive breast cancer patients is a major underlying reason why adjuvant chemotherapy works particularly well for those patients", belies this importance. Therefore, I was delighted to accept the invitation to write a commentary to draw attention to a paper, the significance of which, if fully appreciated, might change the direction of research into breast cancer.

Like all revolutionary ideas it so challenges conventional belief (dogma) that one can expect a knee jerk rejection from those who have an intellectual or financial investment in the received wisdom, to either ignore or react with irrational anger to its implicit message. What the authors are in fact suggesting is that the act of surgery kick starts "latent" metastases of patients with "early" breast cancer into an active state of vascularization and proliferation. This not only accounts for the effect described in the title, but importantly, also explains the paradox of screening in younger women where we see an excess of breast cancer deaths in the screened group within the first few years [2]. This observation so enrages the screening zealots that anyone who draws attention to this counter-intuitive observation [3]. Perhaps now that we have a mechanism to explain this finding, the more open minded in the scientific community might begin to believe in it.

What we now have is a new model of the disease that owes its genesis, in part, to the interpretation of the results of natural history databases and clinical trials, by way of hazard rate plots rather than Kaplan Meyer curves.

We can now see a new signal appearing against background noise, which challenges the assumption of linear dynamics in favour of non-linear mathematics or chaos theory [4]. This "signal" is the early peak of hazard for relapse that follows surgery within 12 to 24 months, whereas the near constant hazard thereafter might be the "echo" of the natural history of breast cancer left unperturbed by surgical interference. If that is true then the act of wounding the patient by surgery creates a favourable environment for the sudden transfer of a micrometatasis from a latent to an active phase.

The most obvious prediction of the model would be that natural or evolutionary advantageous biological events following wounding would also favour cancer progression as a side effect. (It should be remembered in this context that most cancers are the consequence of ageing beyond 
the age of reproductive activity that in evolutionary terms is neutral). In fact, work published in 2004 confirms the similarities in the gene expression of fibroblasts following wounding to those active in malignant disease [5]. Or as Weinberg put it, "The way that tumours acquire the ability to create complex tissues does not involve their de-novo invention of the complex programme of stromal activation. Instead they activate a latent, pre-existing wound-healing programme that is encoded in the normal genome, which they then use as the strategy for constructing their own stroma" [6]. With that in mind we can note with no great surprise a slue of "downstream" epi-phenomena linking molecular events that favour wound healing to the progression and prognosis of breast cancer. For example, HER2 over-expression is closely linked with the expression of vascular endothelial growth factor (VEGF) [7], both of which are associated with a poor prognosis. The fluid from surgical drains is very potent in stimulating epithelial and endothelial cells and this is directly proportional to the magnitude of the operation and indirectly to the age of the patient [8]. Cyclooxygenase (COX)-2 expression is associated with an aggressive phenotype of duct carcinoma in situ [9] and the angiogenicity of circulating malignant cells in the peripheral blood of breast cancer patients predicts for early relapse and resistance to chemotherapy [10]. Finally the paradoxical "curative" effect of adjuvant tamoxifen might be as much to do with its inhibition of the secretion of VEGF as to its anti-oestrogenic effect [11].

To my way of thinking the therapeutic consequences of this belief system go way beyond the modest predictions in the paper that provoked this commentary and suggest that the next leap forward would depend on "stabilizing" these latent metastases with a combination of anti-angiogenic, anti-proliferative and pro-apoptotic therapies before letting a surgeon near a patient. Perhaps the fact that I speak as a surgeon will add credibility to these ideas.

\section{Competing interests}

None declared.

\section{References}

1. Retsky M, Bonadonna G, Demicheli R, Folkman J, Hrushesky W, Valagussa P: Hypothesis: Induced angiogenesis after surgery in premenopausal node-positive breast cancer patients is a major underlying reason why adjuvant chemotherapy works particularly well for those patients. Breast Cancer Res 2004, 6: R372-R374.

2. Baines C: Mammography screening: are women really giving informed consent? J Nat Cancer Inst 2003, 95:1508-1511.

3. Baum M: Who truly represents the needs of the consumer diagnosed with breast cancer? Who are these patients' advocates? How are they informed? What, if any, are their secret agendas? Eur J Cancer 1997, 33:807-808.

4. Baum M, Chaplain MAJ, Anderson ARA, Douek M, Vaidya JS: Does breast cancer exist in a state of chaos? Eur $J$ Cancer 1999, 35:886-891.

5. Chang HY, Sneddon JB, Alizadeh AA, Sood R, West RB, Montgomery K, Chi JT, Rijn Mv M, Botstein D, Brown PO: Gene expression signature of fibroblast serum response predicts human cancer progression: Similarities between tumours and wounds. PLOS Biol 2004, 2:E7.

6. Martina Habeck: Wound-healing genes promote cancer progression. Lancet Oncol 2004, 5:138.

7. Kumar R, Yarmand-Bagheri R: The role of Her2 in angiogenesis. Semin Oncol 2001, 289 (suppl 16):27-32.

8. Tagliabue E, Agresti R, Ghirelli C, Morelli C, Menard S: The early relapse of premenopausal patients after surgery for node positive breast cancer. Breast Cancer Res Treat 2001, 70:155156.

9. Boland GP, Butt IS, Prasad R, Knox WF, Bundred NJ: COX-2 expression is associated with an aggressive phenotype of ductal carcinoma in situ. Br J Cancer 2004, 90:423-429.

10. Giatromanolaki A, Koukourakis Ml, Kakolyris S, Mavroudis D, Kouroussis C, Mavroudi C, Perraki M, Sivridis E, Georgoulias V: Assessment of highly angiogenic and disseminated cancer cells in the peripheral blood in breast cancer patients predicts for resistance to adjuvant chemotherapy and early relapse. Int J Cancer 2004, 108:620-627.

11. Garvin S, Dabrosin C: Tamoxifen inhibits secretion of vascular endothelial growth factor in vivo. Cancer Res 2003, 63:87428748. 